\title{
One-pot synthesis of alkylammonium-functionalized mesoporous silica hollow spheres in water and films at the air-water interface
}

\author{
Sung Soo Park ${ }^{1} \cdot$ Bruno Ameduri $^{2} \cdot$ Chang-Sik Ha $^{1}$
}

Received: 26 December 2018 / Accepted: 21 February 2019 / Published online: 5 March 2019

(C) The Author(s) 2019

\begin{abstract}
This paper reports a one-pot sol-gel approach for the synthesis of the alkylammonium-functionalized mesoporous silica particles with hollow structures and mesoporous silica films via hydrothermal reaction through the self-assembly of Ntrimethoxysilylpropyl-N,N,N-trimethylammonium chloride (TMAPS) and tetraethoxysilane (TEOS) as a silica source, dodecyldimethyl(3-sulfopropyl)ammonium hydroxide (DDAPS) and fluorocarbon anion (ammonium perfluorooctanoate (APFO)) as the structure-directing agent. The alkylammonium-functionalized hollow mesoporous silica particles exhibited a different morphology, mesoporosity, and hollow structure with a layered mesostructure in the shell according to the DDAPS/ APFO surfactant molar ratios (DDAPS/APFO $=3 / 1 \sim 1 / 9$ or APFO in the range of $10 \sim 80 \mathrm{mM}$ ), reaction times $(6 \sim 48 \mathrm{~h}$ ), and reaction temperatures $\left(45 \sim 95{ }^{\circ} \mathrm{C}\right)$. Alkylammonium-functionalized hollow mesoporous silica particles with spherical morphologies were produced from precipitation in the bottom of the reaction bottle after the hydrothermal reaction. At a DDAPS/APFO surfactant ratio of $1 / 3$, reaction temperature of $60^{\circ} \mathrm{C}$, and reaction times of $24 \mathrm{~h}$ and $48 \mathrm{~h}$, the alkylammonium-functionalized hollow mesoporous silica spheres displayed a multilayered mesostructure in the shell. The sphere size could be controlled from ca. $76 \mathrm{~nm}$ to ca. $350 \mathrm{~nm}$ with a shell thickness of ca. $35 \mathrm{~nm}$. In addition, alkylammonium-functionalized mesoporous silica films were produced at the air-water interface, whereas hollow mesoporous silica spheres were produced with precipitation in the bottom of the reaction bottle. The film thickness was controlled from ca. $210 \mathrm{~nm}$ to ca. $400 \mathrm{~nm}$.
\end{abstract}

Keywords Alkylammonium-functionalized mesoporous silica $\cdot$ Air-water interface $\cdot$ Fluorinated anion surfactant $\cdot$ Hollow and film mesoporous silica $\cdot$ One-pot synthesis

\section{Introduction}

Morphological control and the texture of mesoporous materials are extremely important for their function and utility in many applications [1-3]. Hollow mesoporous silica materials that possess large pores inside the shells and mesopores at the

Electronic supplementary material The online version of this article (https://doi.org/10.1007/s42247-019-00028-6) contains supplementary material, which is available to authorized users.

Chang-Sik Ha

csha@pusan.ac.kr

1 Department of Polymer Science and Engineering, Pusan National University, Busan 46241, Republic of Korea

2 Ingénierie et Architectures Macromoléculaires, Institut Charles Gerhardt, CNRS, Univ. Montpellier, Ecole Nat Sup de Chimie de Montpellier, 240 avenue du Professeur Emile JEANBRAU, 34296 Montpellier Cedex 05, France shells are quite attractive in many areas, such as confined catalysis [4-9], biomedicine including drug delivery, bioimaging, cancer cell detection, biosensing [3, 4, 10-13], adsorption of protein and virus [14], and low- $k$ applications [15], owing to their low density, large void space fraction, high surface area, and functionality of shells. The methods widely adapted for the synthesis of hollow mesoporous silica materials generally involve strategies based on sonochemical methods [16], soft-templating methods including emulsion templating and vesicle templating routes [10, 17-27], and hard-templating methods, including polymer latex, silica spheres, carbon spheres, and magnetic nanoparticles as core templates [10, 28-32].

The sol-gel/emulsion method is a useful approach for the synthesis of hollow mesoporous silica materials by a one-pot process via the self-assembly of an organic template (surfactant or polymer) as a structure-directing agent and an inorganic precursor as the wall composition in the reactant solution. In this method, organic templates have generally been used with single 
$[4,22,26,33-37]$, binary $[4,24,26,27,38,39]$, and ternary systems [4, 40]. Teng et al. [33] prepared hollow mesoporous silica spheres by a sol-gel/emulsion (oil-in-water/ethanol) approach using cetyltrimethylammonium bromide $(\mathrm{CTAB})$ as the surfactant and tetraethoxysilane (TEOS) as the inorganic precursor. Li et al. [36] synthesized hollow mesoporous silica nanoparticles (HMSNs) using a Gemini surfactant as a kinetic self-assembly template and TEOS as the silica source. Zhang et al. [37] prepared hollow silica spheres with a mesoporous shell perforated by hexagonally arrayed cylindrical nanochannels through a one-pot sol-gel/emulsion approach using triblock copolymer $\left\{(\mathrm{EO})_{20}(\mathrm{PO})_{70}(\mathrm{EO})_{20}, \mathrm{P} 123\right\}$ as the structure-directing agent and TEOS as the silica precursor. $\mathrm{Wu}$ et al. [38] synthesized rod-like hollow mesoporous silica particles with ordered mesopores parallel to the axis using a surfactant mixture composed of zwitterionic and anionic surfactants as the templates with the assistance of a co-structure-directing agent (CSDA). In addition, Wu and Crudden [39] synthesized uniform helical silica nanotubes and hollow silica nanostructures through the self-assembly of sodium dodecyl sulfate (SDS) as the surfactant, N-trimethoxysilylpropyl-N,N,Ntrimethylammonium chloride (TMAPS) as a co-structuredirecting agent (CSDA), a binaphthyl-based chiral dopant, and TEOS as the bulk silica constituent. Shi's group [27] prepared hollow mesoporous silica spheres (HMSSs) with a mean diameter of $180 \mathrm{~nm}$ and magnetic-functionalized HMSSs via a one-step facile route using the amphiphilic polystyrene- $b$-poly(acrylic acid) block copolymer $\left(\mathrm{PS}_{215}-b-\mathrm{PAA}_{12}\right)$ and the cationic surfactant, CTAB as the co-templates. Moreover, hollow silica spheres with mesostructured shells (HSSMS) obtained with a vesicle template of CTAB-SDS-Pluronic P123 ( $\mathrm{C}_{16}$ TMABSDS- $\mathrm{EO}_{20} \mathrm{PO}_{70} \mathrm{EO}_{20}$ ) ternary surfactants and sodium silicate as the silica source were high-lighted by Lin's group [40]. In contrast to hydrogenated surfactants, partially fluorinated [41] surfactants are prone to form low-curvature structures, such as discs, bilayers, and vesicles [23]. Several researchers reported the synthesis of hollow mesoporous silica materials using fluorinated surfactants as structure-directing agents or co-template. Rankin's group [22] reported the synthesis of spherical hollow silica particles with a single layer of mesopores in their shells through a sol-gel process using a fluorinated surfactant (perfluorodecylpyridium chloride) as the template. The same team also described the synthesis of organic-inorganic hybrid hollow particles using the fluorinated pyridinium surfactant [1-(10-perfluorooctyldecyl)pyridinium bromide] as a template and alkoxysilanes with bridged organic groups and TEOS as the silica sources [23]. Djojoputro et al. [24] suggested the preparation of periodic mesoporous organosilica (PMO) hollow spheres with a tunable wall thickness by a liquid crystal dual templating approach using a fluorocarbon surfactant $\left[\mathrm{C}_{3} \mathrm{~F}_{7} \mathrm{O}\left(\mathrm{C} \mathrm{F}\left(\mathrm{C} \mathrm{F}_{3}\right) \mathrm{C} \mathrm{F}_{2} \mathrm{O}\right)_{2} \mathrm{CF} \mathrm{C} \mathrm{F}_{3}-\right.$ $\mathrm{CONH}\left(\mathrm{CH}_{2}\right)_{3} \mathrm{~N}^{+}\left(\mathrm{C}_{2} \mathrm{H}_{5}\right)_{2} \mathrm{CH}_{3} \Pi$ ( $\left.\mathrm{FC} 4\right)$ and cationic surfactant, $\mathrm{CTAB}$, as the template, and 1,2-bis(trimethoxysilyl)ethane
(BTME) as the hybrid silica precursor. They also detailed the preparation of a novel PMO magnetic hollow sphere (PMOMHS) by embedding the monodispersed magnetite nanocrystals into the cavities of highly ordered PMO hollow spheres using FC4, BTME, and $\mathrm{Fe}_{3} \mathrm{O}_{4}$ nanoparticles stabilized with $\mathrm{CTAB}$ as the template, the organosilica source, and the magnetic species, respectively [35]. The synthesis of multishelled mesoporous silica hollow nanospheres (MMSHNs) through a facile vesicle template approach derived from the self-assembly of surfactants $\left\{\mathrm{FC} 4\right.$ and $\mathrm{EO}_{106} \mathrm{PO}_{70} \mathrm{EO}_{106}$ (F127)\} was reported by Qiao's group [26].

Hollow mesoporous silica materials with a functionalized mesoporous surface may have extended applicability compared to pure hollow mesoporous silica materials in various applications, such as those mentioned above [1-15].

Generally, there are two approaches to surface and framework functionalization: direct synthesis or co-condensation and post-synthesis or grafting [3, 25]. The direct synthesis/cocondensation method may offer a high loading and more homogeneous distribution of functional groups with a shorter preparation time via a one-pot synthesis process compared to the post-synthesis or grafting method $[3,25]$. Several researchers mentioned the synthesis of the functionalized hollow mesoporous silica materials via a one-pot synthesis process by a co-condensation method using alkoxysilanes with the bridged organic groups (ethylene, methylene, phenylene) $[23-25,34$, $35]$ and terminal organic groups (propylammonium, thiol, amine, cyanide, ethylene, phenyl) $[25,38,39]$, and TEOS as the silica sources. The alkylammonium-functionalized mesoporous silica materials with a hollow sphere morphology that simultaneously possess large pores inside the shells and mesopores at the shells can be quite attractive for a range of application fields, such as confined catalysis, biomedicine (including drug delivery), bioimaging, cancer cell detection, biosensing, adsorption of protein and virus, and low- $k$ application, because of their large void space fraction, high surface area, and functionality of shells [3-15].

The morphology of the mesoporous silica materials often controls their function and utility. Ozin's group [42] first reported the production of mesoporous silica films at the air-water interface via a hydrothermal reaction through the self-assembly of TEOS as the silica precursor and cetyltrimethylammonium chloride $(\mathrm{CTACl})$ as the structure-directing agent. A previous study described the synthesis of free-standing PMO films with bridged ethane, benzene, and amine organic moieties in the framework at the air-water interface, while PMO materials with the powder morphologies were produced with precipitation in the bottom of the reaction bottle via a hydrothermal reaction [43-46].

To the best of the authors' knowledge, there are no reports of the synthesis of the functionalized mesoporous organosilica films at the air-water interface with the concomitant production of hollow mesoporous silica materials in the bottom of the reaction 
bottle. This paper presents for the first time a one-pot sol-gel approach for the synthesis of the alkylammoniumfunctionalized hollow mesoporous silica materials via a hydrothermal reaction through the self-assembly of $\mathrm{N}$ trimethoxysilylpropyl-N,N,N-trimethylammonium chloride (TMAPS) and TEOS as the silica source, and dodecyldimethyl(3-sulfopropyl)ammonium hydroxide (DDAPS) and fluorocarbon anion (ammonium perfluorooctanoate (APFO)) as the structure-directing agents. In particular, we focused on studying the effects of fluorocarbon as structure-directing agent in this experiment. Functionalized mesoporous organosilica films were produced at the air-water interface, while hollow mesoporous silica powders were obtained with precipitation at the bottom of the reaction bottle.

\section{Experimental section}

\subsection{Chemicals}

N-Dodecyl-N,N-dimethyl-3-ammonio-1-propanesulfonate (DDAPS, > 98\%) was purchased from TCI. Ntrimethoxysilypropyl-N,N,N-trimethylammonium chloride (TMAPS, $50 \%$ in $\mathrm{MeOH}$ ) was obtained from Gelest. Ammonium perfluorooctanoate (APFO, > 98\%), tetraethoxysilane (TEOS, 98\%), and triethanolamine (98\%) were supplied by Aldrich. All chemical agents were used as received.

\subsection{Synthesis of the alkylammonium-functionalized hollow mesoporous silica spheres and films}

In a typical synthesis of the alkylammonium-functionalized hollow mesoporous silica spheres and films, $6 \mathrm{mmol}$ of triethanolamine was added to a $20 \mathrm{~mL}$ surfactant mixture solution $\left(c_{\text {total }}=10 \mathrm{mM}\right)$ composed of DDAPS/APFO at various molar ratios (DDAPS:APFO = 3:1, 1:1, 1:3, 1:6, and 1:9). DDAPS and APFO were added at a 1:1 molar ratio with stirring, followed by the addition of $0.5 \mathrm{~mL}$ of $\mathrm{NH}_{3} \cdot 3 \mathrm{H}_{2} \mathrm{O}$ $\left(2.5 \% \mathrm{NH}_{3}\right)$, and then by $112 \mu \mathrm{L}(0.2 \mathrm{mmol})$ of TMAPS and $315 \mu \mathrm{L}$ of TEOS. The mixture was then stirred for $30 \mathrm{~min}$ at $45^{\circ} \mathrm{C}$. The resulting solution was placed in an oven at 45,60 , and $95{ }^{\circ} \mathrm{C}$ for $6,12,24$, and $48 \mathrm{~h}$ under static conditions. Functionalized mesoporous organosilica films were produced at the air-water interface while hollow mesoporous silica powders were produced by precipitation in the bottom of the reaction bottle.

The product was separated by filtration, washed with ethanol and water, and dried at $60{ }^{\circ} \mathrm{C}$ for $12 \mathrm{~h}$. Removal of the surfactants was performed twice through a solvent extraction process under a $\mathrm{HCl} / \mathrm{ethanol}$ solution at $60{ }^{\circ} \mathrm{C}$ for $12 \mathrm{~h}$ [43-46].

The powder products were labeled HMS $X Y-T-t$, where $X Y$, $T$, and $t$ denote the molar ratio of DDAPS/APFO, heating temperature, and reaction time, respectively. The film samples were labeled HMS $X Y-T-t F$.

The alkylammonium-functionalized hollow mesoporous silica materials were also synthesized using APFO as a single structure-directing agent with different concentrations (10 mM, $20 \mathrm{mM}, 40 \mathrm{mM}$, and $80 \mathrm{~mm})$. The other process was the same as that for HMSXY-T-t. The powder products were labeled HMSCS- $T$ - $t$, where $C$ represents the concentration of APFO, $T$ is the heating temperature, and $t$ is reaction time. The film products were labeled HMSCS-T- $t F$.

\subsection{Characterization}

$\mathrm{X}$-ray diffraction (XRD) was performed using a conventional $\mathrm{X}$-ray diffractometer [Rigaku Miniflex, $\mathrm{Cu}-\mathrm{Ka}(\lambda=$ $1.5418 \AA)]$. The nitrogen adsorption and desorption isotherms were measured at $-196{ }^{\circ} \mathrm{C}$ using a Nova 4000e instrument. The specific surface area of the samples was obtained from the adsorption branch of the isotherm using the BrunauerEmmett-Teller (BET) method [47] at relative pressures, ranging from 0.05 to 0.20 . The total pore volume [48] was estimated from the amount adsorbed at a relative $P / P_{o}$ of 0.99 , where $P$ and $P_{o}$ denote the equilibrium pressure and saturation vapor pressure, respectively. The pore size distribution curve was obtained from an analysis of the adsorption branch using the Barrett-Joyner-Halenda (BJH) method. Scanning electron microscopy (SEM, KEVEX Sigma) was performed at an acceleration voltage of $20 \mathrm{kV}$. The samples were coated with gold using a Hitachi E-1010 sputter coater prior to imaging. The transmission electron microscopy (TEM, JEOL 2010) images were recorded at $200 \mathrm{kV}$. Fourier transform infrared (FT-IR, Perkin Elmer) spectroscopy of the materials was performed using $\mathrm{KBr}$ pellets over the wavenumber range, 400 $4000 \mathrm{~cm}^{-1}$.

\section{Results and discussion}

Scheme 1 presents the synthesis process of the alkylammonium-functionalized hollow mesoporous silica spheres and film preparation. The materials were synthesized via the self-assembly of templates (DDAPS and APFO) and silica precursors (TMAPS and TEOS), and a hydrothermal reaction process using a one-pot sol-gel approach.

Figure 1 shows SEM images of the alkylammoniumfunctionalized hollow mesoporous silica materials synthesized at $60^{\circ} \mathrm{C}$ for $24 \mathrm{~h}$ at different DDAPS/APFO molar ratios as the structure-directing agents: (a,f) HMS31-60-24h, $(\mathrm{b}, \mathrm{g})$ HMS11-60-24h, (c,h) HMS13-60-24h, (d,i) HMS16-60-24h, and (e,j) HMS19-60-24h. Regardless of the DDAPS/APFO ratio, all samples exhibited spherical morphologies. SEM images indicated that HMS31-60-24h, HMS13-60-24h, HMS16-60-24h, and HMS19-60-24h had particle sizes of 
Scheme 1 Schematic illustration for synthesis of the alkylammonium-functionalized hollow mesoporous silica spheres and films via self-assembly and hydrothermal reaction

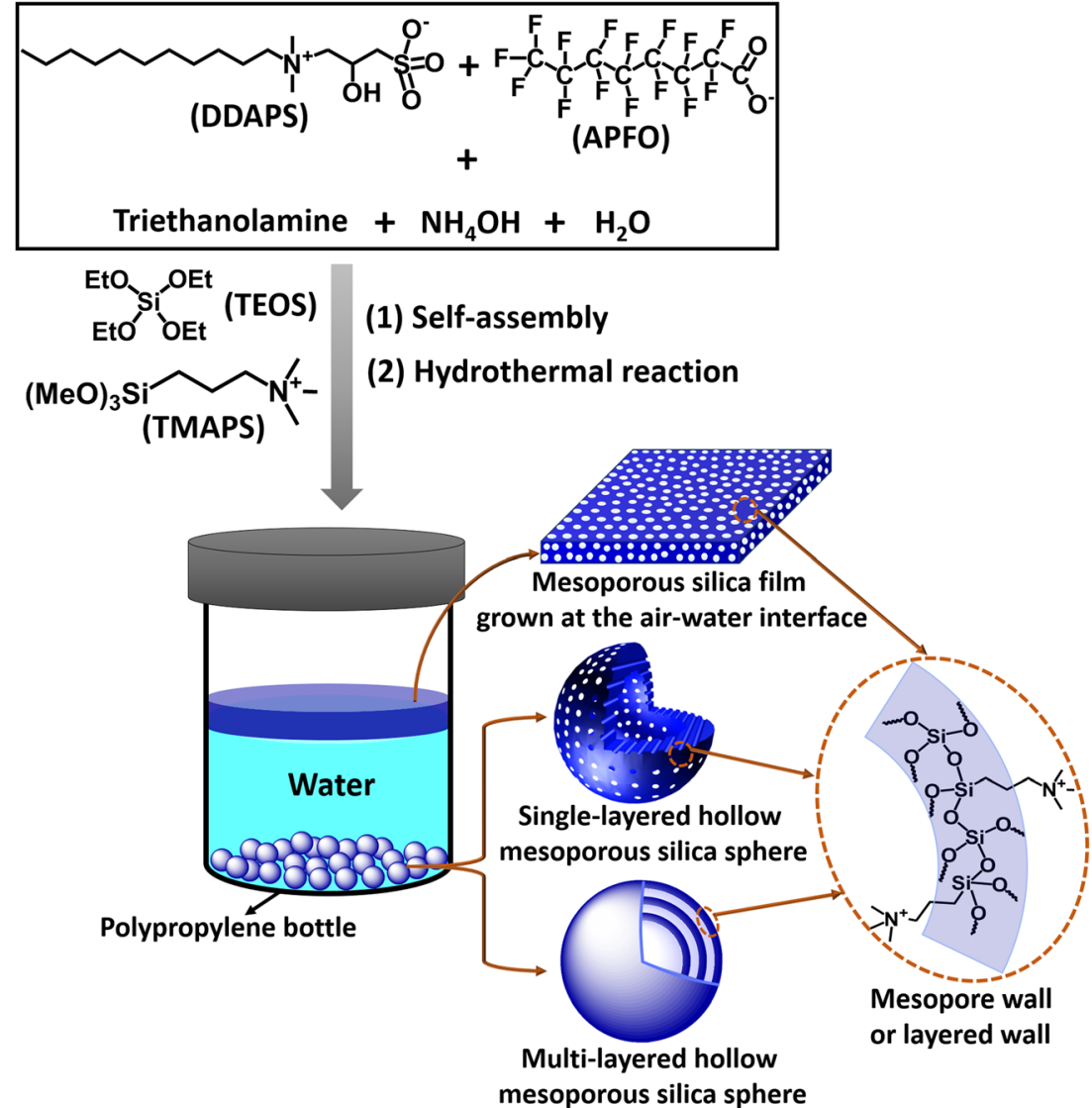

$300, \sim 150, \sim 350$, and $\sim 180 \mathrm{~nm}$, respectively, while HMS11$60-24 \mathrm{~h}$ was composed of both large particles of $\sim 300 \mathrm{~nm}$ and somewhat aggregated small particles of $\sim 80 \mathrm{~nm}$ in size.

Figure 2 presents TEM images of the alkylammoniumfunctionalized hollow mesoporous silica materials synthesized at $60{ }^{\circ} \mathrm{C}$ for $24 \mathrm{~h}$ using different DDAPS/APFO structure-directing agent ratios: (a,f) HMS31-60-24h, (b,g) HMS11-60-24h, (c,h) HMS13-60-24h, (d,i) HMS16-60-24h, and (e,j) HMS19-60-24h. HMS31-60$24 \mathrm{~h}$ synthesized with a low APFO ratio (DDAPS/ $\mathrm{APFO}=3 / 1$ ) exhibited a mesostructured spherical morphology. For APFO to DDAPS/APFO = 1/1, even though the shells illustrated disordered mesostructured (as evidenced in the XRD patterns with the broad peaks of Fig. S1), the sample exhibited a hollow structure with a mesostructured shell with double layers. Although HMS13-60-24h and HMS19-60-24h displayed a broad peak at approximately $2^{\circ} 2 \theta$, the alkylammoniumfunctionalized hollow mesoporous silica materials did not show noticeable XRD patterns in the range of $1.2-10^{\circ} 2 \theta$ (Fig. S1). The results suggest that the hollow mesoporous silica materials have disordered mesostructures. For DDAPS $/ \mathrm{APFO}=1 / 3$, the alkylammonium-functionalized mesoporous silica materials have a clearer sphere morphology with a multilayered shell. This vesicular structure was similar in structure to the multilayered particles reported by Tanev and Pinnavaia [49]. Interdigitation of the bilayer composed of DDAPS and APFO micelles is believed to be a key feature leading to the stability of bilayers supported on colloidal particles, where the fluorination of lipids has been reported to induce the formation of interdigitated bilayers [23]. At a DDAPS/ APFO ratio of 1/9, the multilayered structures of the samples were destroyed while the hollow spherical morphology was retained with a shell thickness of approximately $35 \mathrm{~nm}$.

Figure 3 exhibits the $\mathrm{N}_{2}$ sorption isotherm curves of the alkylammonium-functionalized hollow mesoporous silica materials synthesized at $60{ }^{\circ} \mathrm{C}$ for $24 \mathrm{~h}$ using different DDAPS/APFO ratios: (a) HMS31-60-24h, (b) HMS11-6024h, (c) HMS13-60-24h, (d) HMS16-60-24h, and (e) HMS19-60-24h. The inset represents the pore size distributions of (a) HMS31-60-24h, (b) HMS11-60-24h, (c) HMS1360-24h, (d) HMS16-60-24h, and (e) HMS19-60-24h. Table 1 lists the textural properties of the samples. With increasing APFO ratio (from DDAPS/APFO $=3 / 1$ to $1 / 3$ ), the surface area, pore volume, and pore diameter exhibited a decreasing trend from 319 to $197 \mathrm{~m}^{2} \mathrm{~g}^{-1}, 0.38$ to $0.25 \mathrm{~cm}^{3} \mathrm{~g}^{-1}$, and 45.0 to $31.5 \AA$, respectively. For DDAPS/APFO $=1 / 6$, the surface area and pore volume increased to $296 \mathrm{~m}^{2} \mathrm{~g}^{-1}$ and $0.35 \mathrm{~cm}^{3} \mathrm{~g}^{-1}$, respectively. HMS16-60-24h and HMS19-60- 
Fig. 1 Low (a-e) and high (f-j) magnified SEM images of the alkylammonium-functionalized hollow mesoporous silica materials synthesized at $60^{\circ} \mathrm{C}$ for $24 \mathrm{~h}$ using different DDAPS/ APFO ratios: (a,f) HMS31-6024h, (b,g) HMS11-60-24h, (c,h) HMS13-60-24h, (d,i) HMS1660-24h, and (e,j) HMS19-60-24h
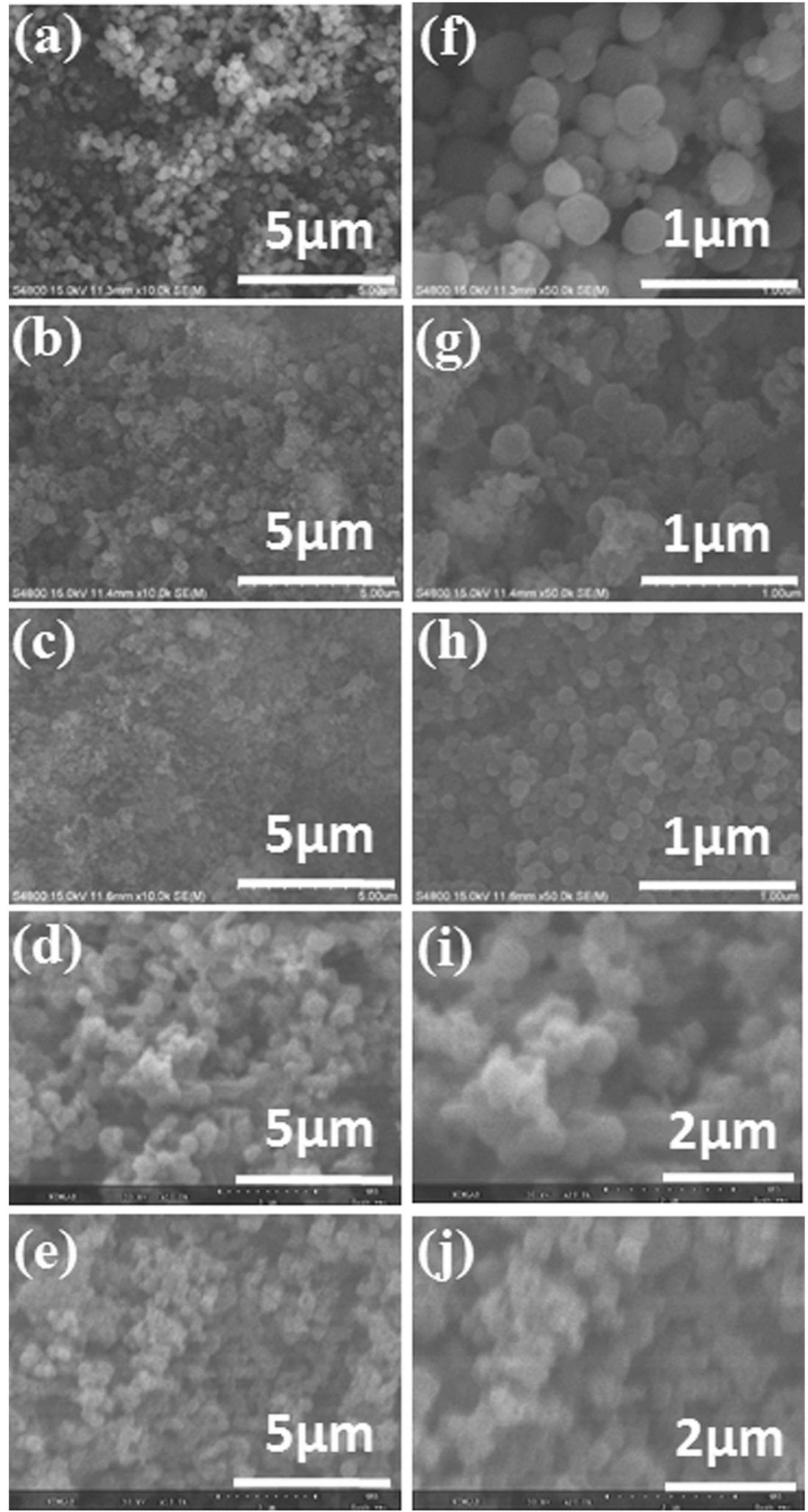

24h did not show any noticeable pore size distributions due to typical mesopores below $100 \AA$. The pore size distribution of $100 \AA$ and over may arise from the hollow structure and voids of the inter-hollow silica particles.
FT-IR spectroscopy was performed to determine if alkylammonium alkoxysilane was incorporated in the mesopore walls (Fig. S2). Both samples of as-synthesized HMS13-60-24h (Fig. S2(a)) and surfactant-extracted 
Fig. 2 Low (a-e) and high (f-j) magnified TEM images of the alkylammonium-functionalized hollow mesoporous silica materials synthesized at $60^{\circ} \mathrm{C}$ for $24 \mathrm{~h}$ using different DDAPS/ APFO ratios: (a,f) HMS31-6024h, (b,g) HMS11-60-24h, (c,h) HMS13-60-24h, (d,i) HMS1660-24h, and (e,j) HMS19-60-24h
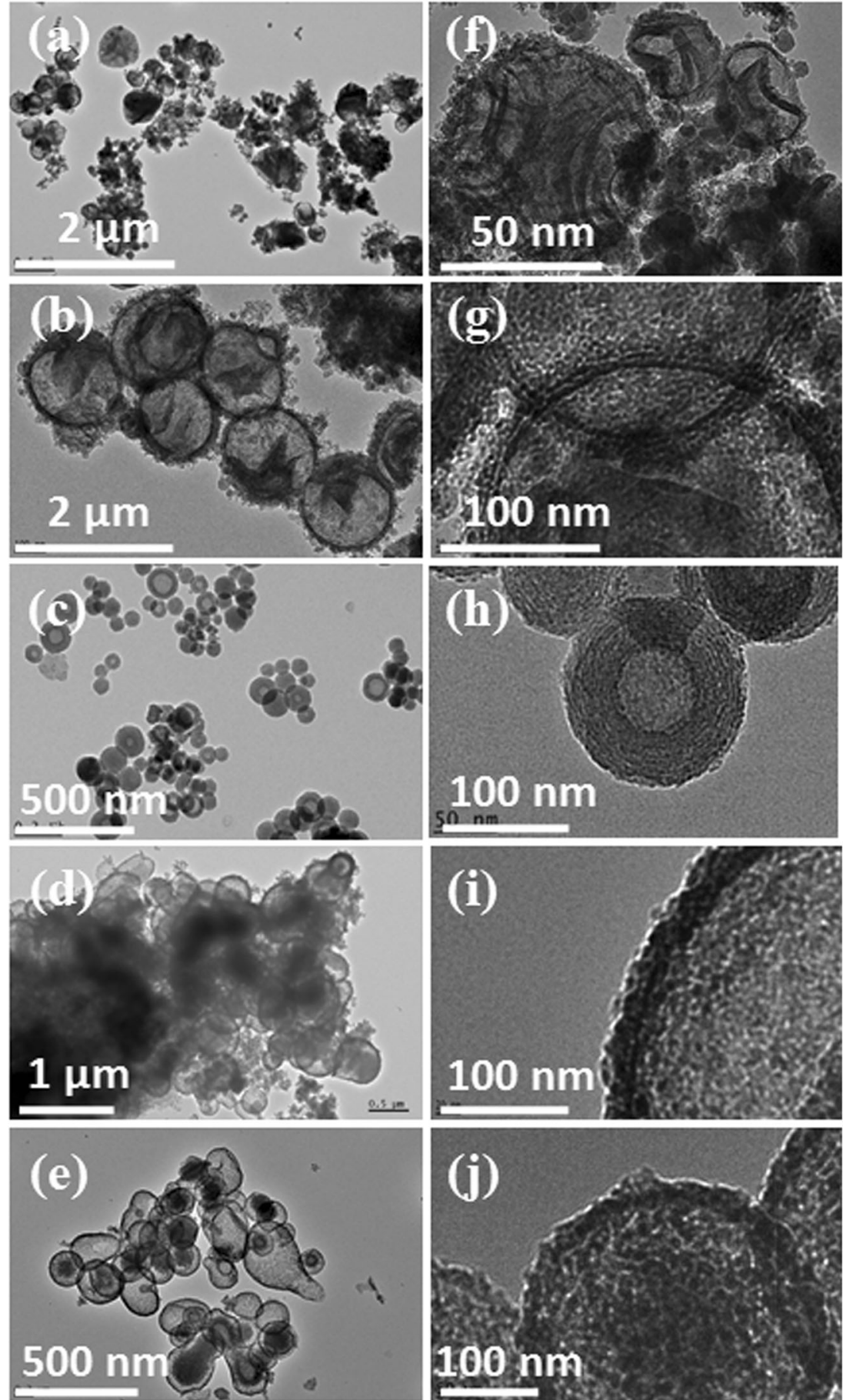

HMS13-60-24h (Fig. S2(b)) exhibited characteristic peaks at 793 and $1063 \mathrm{~cm}^{-1}$ and at $955 \mathrm{~cm}^{-1}$, which were assigned to $\mathrm{Si}-\mathrm{O}-\mathrm{Si}-$ and $\mathrm{Si}-\mathrm{OH}$ groups, respectively. A prominent peak at $1483 \mathrm{~cm}^{-1}$ was attributed to $-\mathrm{C}-\mathrm{N}^{+}$in alkylammonium alkoxysilane in the mesopore walls. The peak indicates that the alkylammonium moieties exist without any damage to the mesopore walls after surfactant-extraction. Interestingly, the alkylammonium-functionalized mesoporous silica films were synthesized at the air-water interface at the same time as the production of hollow mesoporous silica powders in the bottom of the reaction bottle.

Figure 4 shows the $(\mathrm{a}, \mathrm{c})$ low- and $(\mathrm{b}, \mathrm{d})$ high-magnified SEM images of (a,b) HMS13-60-24hF and (c,d) HMS19$60-24 \mathrm{hF}$ synthesized at $60{ }^{\circ} \mathrm{C}$ for $24 \mathrm{~h}$ with the DDAPS/

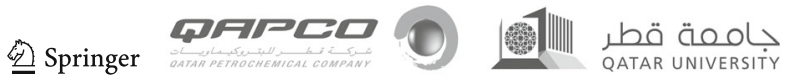


Fig. $3 \mathrm{~N}_{2}$ sorption isotherm curves of the alkylammoniumfunctionalized hollow mesoporous silica materials synthesized at $60^{\circ} \mathrm{C}$ for $24 \mathrm{~h}$ using different DDAPS/APFO ratios: (a) HMS31-60-24h, (b) HMS11-60-24h, (c) HMS13-6024h, (d) HMS16-60-24h, and (e) HMS19-60-24h. Insert shows pore size distributions of (a) HMS31-60-24h, (b) HMS11-6024h, (c) HMS13-60-24h, (d) HMS16-60-24h, and (e) HMS19$60-24 \mathrm{~h}$

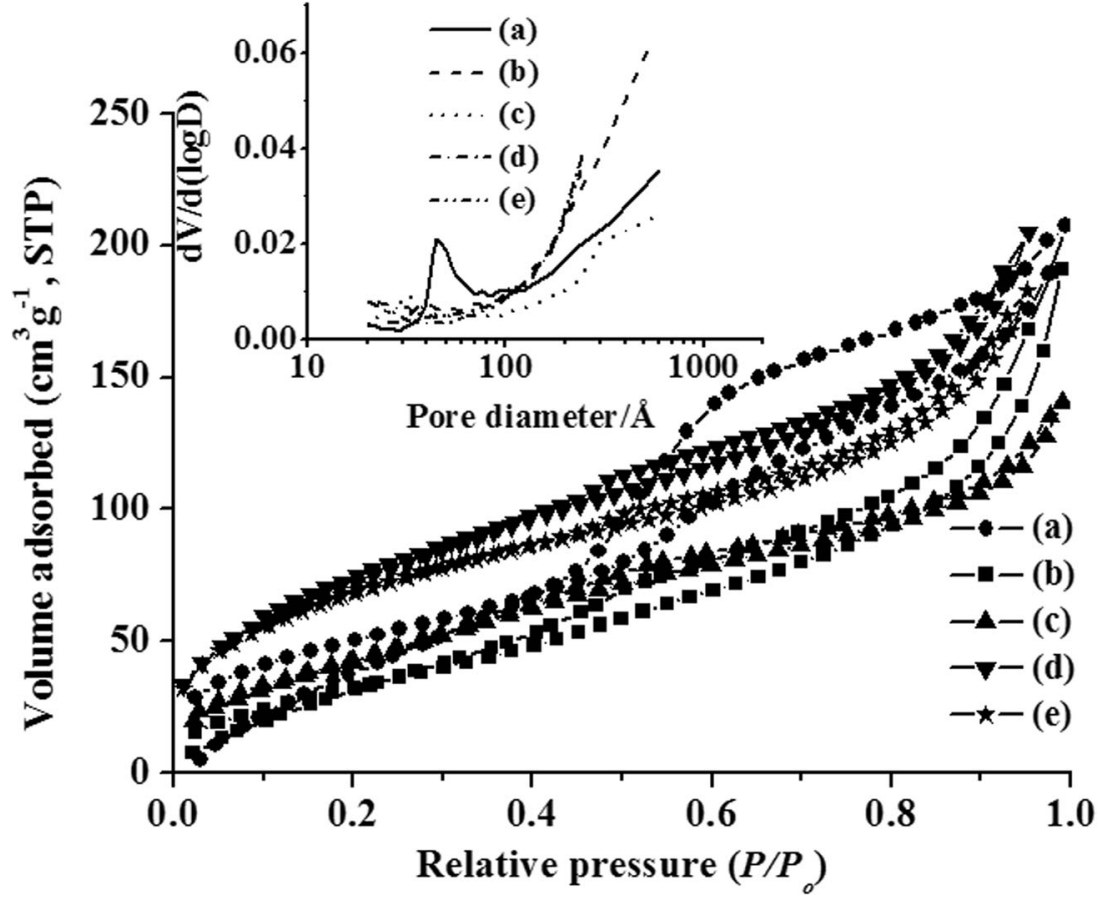

$\mathrm{APFO}=1 / 3$ and $1 / 9$ ratios, respectively. The films had uniform thicknesses of 411 and $254 \mathrm{~nm}$, respectively. HMS3160-24hF, HMS11-60-24hF and HMS19-60-24hF synthesized at $60{ }^{\circ} \mathrm{C}$ for $24 \mathrm{~h}$ with different DDAPS/APFO ratios $(3 / 1,1 / 1$, and 1/6) were also produced at the air-water interface with uniform thicknesses of about $210 \mathrm{~nm}$, ca. $220 \mathrm{~nm}$ and about $400 \mathrm{~nm}$, respectively (Fig. S3).

Figure 5 presents $(\mathrm{a}, \mathrm{b})$ low- and $(\mathrm{c}, \mathrm{d})$ high-magnification TEM images of (a,c) HMS13-60-24hF, (b,d) HMS19-60$24 \mathrm{hF}$. The TEM images clearly show that although the film samples had disordered mesostructures, the films contained mesopores with a uniform size of ca. $30 \AA$ from the TEM image. The results of short-range ordered mesochannels were confirmed by XRD with broad peaks (Fig. S4).

The alkylammonium-functionalized hollow mesoporous silica materials were also synthesized at $60{ }^{\circ} \mathrm{C}$ for different reaction times $(6 \mathrm{~h}, 12 \mathrm{~h}, 24 \mathrm{~h}$, and $48 \mathrm{~h})$. All samples displayed spherical hollow structures with smaller particles compared to HMS13-60-24h (see also Figs. 1c,h and 2c,h), as shown in Fig. 6a, Fig. S5 and Fig. S6(a,b)). Although HMS13-60-48h has a broad XRD peak at approximately $2^{\circ}$ $2 \theta$, the samples exhibited mesostructures in the shells with short-range ordered mesopores (Fig. S7). With increasing reaction time to $48 \mathrm{~h}$, the alkylammonium-functionalized hollow mesoporous silica particles with a shell thickness of ca. $20 \mathrm{~nm}$ had a uniform particle size with ca. $340 \mathrm{~nm}$ (Fig. 6). In particular, TEM (Fig. 6b) revealed multilayers with a distance of ca. $3 \mathrm{~nm}$ between the layers in shell all over the shell of the particles, similar in appearance to the peel of an onion, while some cylindrical mesopores were formed between the layers. As explained for HMS13-60-24h (Fig. 2c,h), this vesicular structure can be achieved by the interdigitation of bilayers composed of DDAPS and APFO micelles all over the particle with a long reaction time (48 h) [23, 49]. After $48 \mathrm{~h}$, alkylammonium-functionalized mesoporous silica with a film morphology (HMS13-60-48hF) was also produced at the air-water interface while the HMS13-60-48h sample was produced by precipitation in the bottom of the reaction bottle. Although the mesostructure had a disordered arrangement of mesopores, the film displayed high mesoporosity with a uniform pore size, as evidenced in the TEM image of Fig. S8(f). As shown in the TEM images (Fig. S8(d,e)), with short reaction times of $6 \mathrm{~h}$ and $12 \mathrm{~h}$, the mesopores in the film were also produced with a uniform pore size.

The alkylammonium-functionalized hollow mesoporous silica materials, HMS13-45-24h and HMS13-95-24h were synthesized for $24 \mathrm{~h}$ at $45^{\circ} \mathrm{C}$ and $95^{\circ} \mathrm{C}$, respectively. Unlike HMS13-45-24h synthesized at $45{ }^{\circ} \mathrm{C}$, HMS13-95$24 \mathrm{~h}$ prepared at $95{ }^{\circ} \mathrm{C}$ showed uniform particle sizes (Fig. S9 and Fig. S10(a,b) and (e,f)). On the other hand, the multilayered structure in the shell was destroyed, as evidenced from the TEM images (Fig. S10(f)). XRD (Fig. S11) showed that both samples (HMS13-45-24h and HMS13-95-24h) have disordered mesostructures without noticeable XRD peaks in the range, $1.2-10^{\circ} 2 \theta$, with a spherical morphology (underlined by TEM, Fig. S10(a,b) and (e,f)). Under these conditions, for the synthesis of HMS13-45-24h and HMS13-95-24h, the alkylammonium-functionalized mesoporous silica films were synthesized at the air-water interface, whereas HMS13-4524h and HMS13-95-24h samples were produced by precipitation in the bottom of the reaction bottle. HMS13-45-24hF

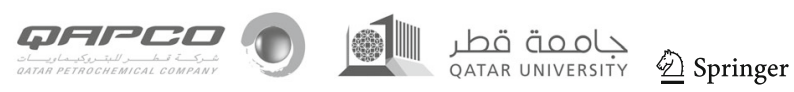


Table 1 Textural properties of the alkylammonium-functionalized hollow mesoporous silica materials synthesized at $60^{\circ} \mathrm{C}$ for $24 \mathrm{~h}$ using different DDAPS/ APFO ratios: (a) HMS31-60-24h, (b) HMS11-60-24h, (c) HMS1360-24h, (d) HMS16-60-24h, and (e) HMS19-60-24h

\begin{tabular}{llllc}
\hline Sample & $\begin{array}{l}\text { DDAPS } / \\
\text { APFO }\end{array}$ & $S_{\text {BET }}\left(\mathrm{m}^{2} \mathrm{~g}^{-1}\right)^{a}$ & $V_{\text {total }}\left(\mathrm{cm}^{3} \mathrm{~g}^{-1}\right)^{b}$ & $D(\AA)^{c}$ \\
\hline HMS31-60-24h & $3 / 1$ & 319 & 0.38 & 45.0 \\
HMS11-60-24h & $1 / 1$ & 183 & 0.34 & 37.7 \\
HMS13-60-24h & $1 / 3$ & 197 & 0.25 & 31.5 \\
HMS16-60-24h & $1 / 6$ & 296 & 0.35 & - \\
HMS19-60-24h & $1 / 9$ & 226 & 0.29 & - \\
\hline
\end{tabular}

${ }^{\mathrm{a}}$ Total surface area, BET method

${ }^{\mathrm{b}}$ Total pore volume

${ }^{\mathrm{c}}$ Pore diameter synthesized at $45{ }^{\circ} \mathrm{C}$ produced mesopores in the film with uniform pore sizes of ca. $30 \AA$ (Fig. S10(c,g)). In contrast, the mesostructure of HMS13-95-24hF synthesized at high temperature $\left(95^{\circ} \mathrm{C}\right)$ was destroyed, as highlighted in Fig. S10(d,h).

On the other hand, alkylammonium-functionalized hollow mesoporous silica materials were obtained at $60^{\circ} \mathrm{C}$ for $24 \mathrm{~h}$ from different APFO concentrations (from 10 to $80 \mathrm{mM}$ ) as a unique structure-directing agent without DDAPS. All materials exhibited spherical morphologies with hollow structures, as shown in Fig. 7, Fig. S12, and Fig. S13. With increasing APFO concentration from 10 to $80 \mathrm{mM}$, the size of the alkylammonium-functionalized hollow mesoporous silica particles decreased from $\sim 190$ to $\sim 76 \mathrm{~nm}$; while when it was increased to $20 \mathrm{mM}$, the particles displayed a uniform size $(\sim 190 \mathrm{~nm}$ and $\sim 150 \mathrm{~nm}$ for HMS10S-60-24h (Fig. 7) and HMS20S-60-24h (Fig. S12(a,d) and Fig. S13(a,d)), respectively) with a hollow structure. On the other hand, hollow mesoporous silica particles were produced with small particles (Fig. S13). The XRD patterns in the range, $1.2-10^{\circ} 2 \theta$, indicated that all the samples have disordered mesostructures without noticeable XRD peaks (Fig. S14).

The $\mathrm{N}_{2}$ sorption behavior confirmed that all samples exhibited mesoporosity with a hollow structure (Fig. S15). With increasing APFO concentration from 10 to $80 \mathrm{mM}$, the surface areas and pore volumes of HMS10S-60-24h, HMS20S-6024h, HMS40S-60-24h, and HMS80S-60-24h samples were $92 \mathrm{~m}^{2} \mathrm{~g}^{-1}$ and $0.11 \mathrm{~cm}^{3} \mathrm{~g}^{-1}, 197 \mathrm{~m}^{2} \mathrm{~g}^{-1}$ and $0.25 \mathrm{~cm}^{3} \mathrm{~g}^{-1}$, $278 \mathrm{~m}^{2} \mathrm{~g}^{-1}$ and $0.54 \mathrm{~cm}^{3} \mathrm{~g}^{-1}$, and $357 \mathrm{~m}^{2} \mathrm{~g}^{-1}$ and $0.79 \mathrm{~cm}^{3}$ $\mathrm{g}^{-1}$, respectively. Table $\mathrm{S} 1$ lists the textural properties of the samples. On the other hand, the pore diameter almost did not change with the order of $\sim 21 \AA$. The result shows that the samples have high porosity with increasing APFO concentration to $80 \mathrm{mM}$. A pore size distribution of $100 \AA$ and over may be due to the hollow structure and voids in the inter-hollow silica particles (Fig. S15(B)).

Figure 8 presents $(\mathrm{a}-\mathrm{c})$ low- and $(\mathrm{e}-\mathrm{g})$ high-magnified TEM images of $(a, e)$ HMS10S-60-6h, $(b, f)$ HMS10S-60$12 \mathrm{~h}$, and (c,g) HMS10S-60-48h synthesized at $60{ }^{\circ} \mathrm{C}$ for
Fig. 4 Low $(a, c)$ and high $(b, d)$ magnified SEM images of $(a, b)$ HMS13-60-24hF and (c,d) HMS19-60-24hF synthesized at $60{ }^{\circ} \mathrm{C}$ for $24 \mathrm{~h}$ with DDAPS/ APFO molar ratios of $1 / 3$ and $1 / 9$, respectively

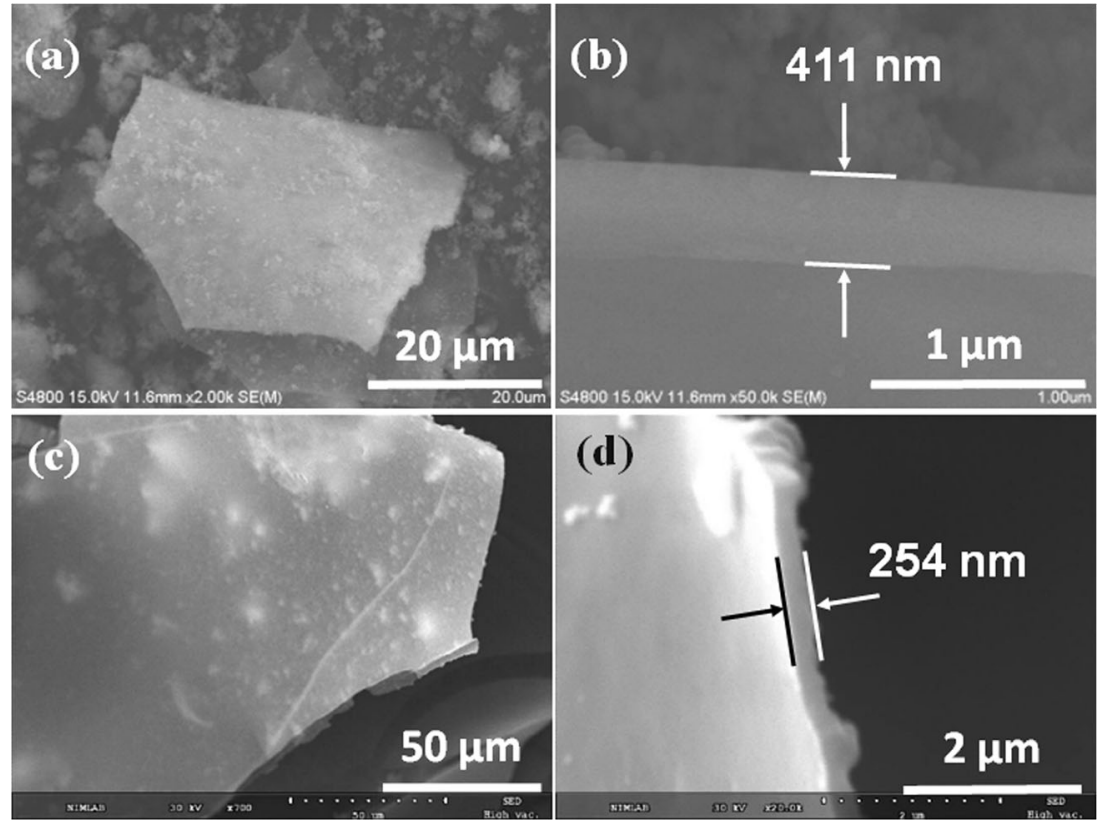


Fig. 5 Low $(a, b)$ and high $(c, d)$ magnified TEM images of $(a, c)$ HMS13-60-24hF and (b,d) HMS19-60-24hF synthesized at $60{ }^{\circ} \mathrm{C}$ for $24 \mathrm{~h}$ with DDAPS/ APFO molar ratios of $1 / 3$ and $1 / 9$, respectively
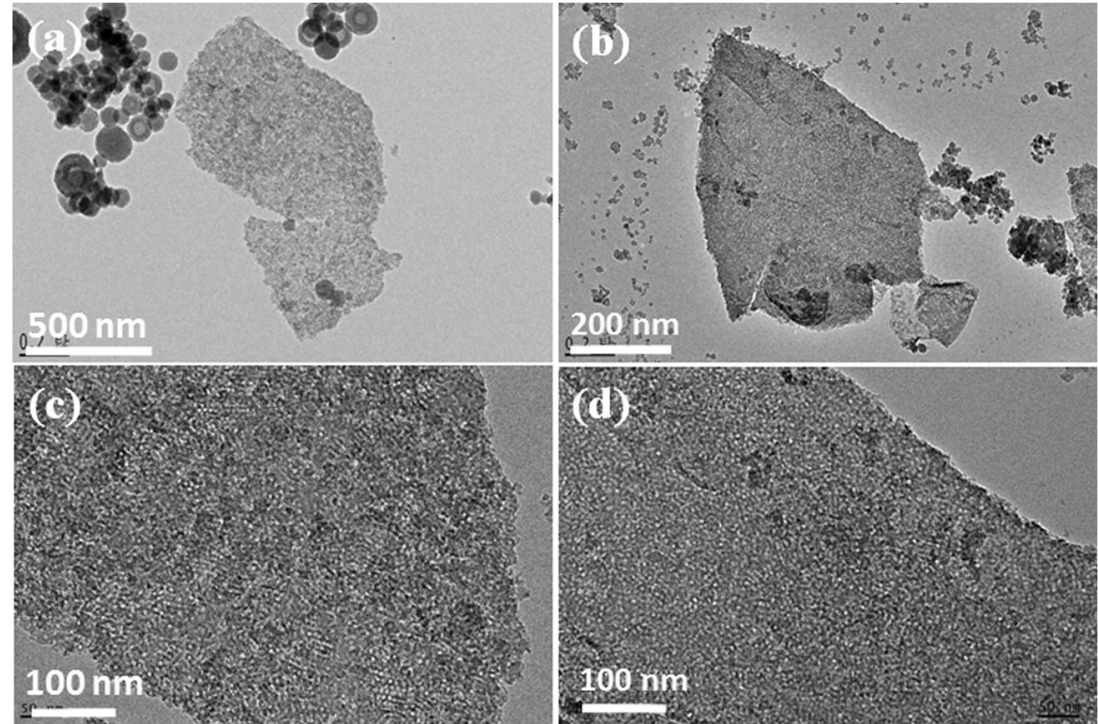

different reaction times ( $6 \mathrm{~h}, 12 \mathrm{~h}$, and $48 \mathrm{~h}$ ) using only APFO as the structure-directing agent. All samples showed that the hollow mesoporous silica particles were obtained with spherical morphologies. This result is supported by SEM (Fig. S16). At a reaction time of $12 \mathrm{~h}$, the hollow structure of HMS10S-60-12h with mesopores in the shell was produced with a patulous morphology, as evidenced by the TEM images (Fig. $8 \mathrm{~b}$ and f). With an increasing reaction time of $48 \mathrm{~h}$, the sample had interesting scallop morphology, as high-lighted by the TEM images (Fig. 8c and g). These samples also had disordered mesostructures as showed in the XRD patterns (Fig. S17). The XRD results match the TEM results (Fig. $8 \mathrm{a}-\mathrm{c}$ and $\mathrm{e}-\mathrm{g}$ ). The film samples were also produced at the air-water interface, whereas alkylammonium-functionalized hollow mesoporous silica particles with spherical morphologies were produced by precipitation in the bottom of the reaction bottle (Fig. 8a-c and e-g). Figure $8 \mathrm{~d}$ and h exhibit (d) low- and (h) high-magnified TEM images of the HMS10S60-6hF sample. Although the mesostructure had a disordered arrangement, the resulting film contained mesopores. At
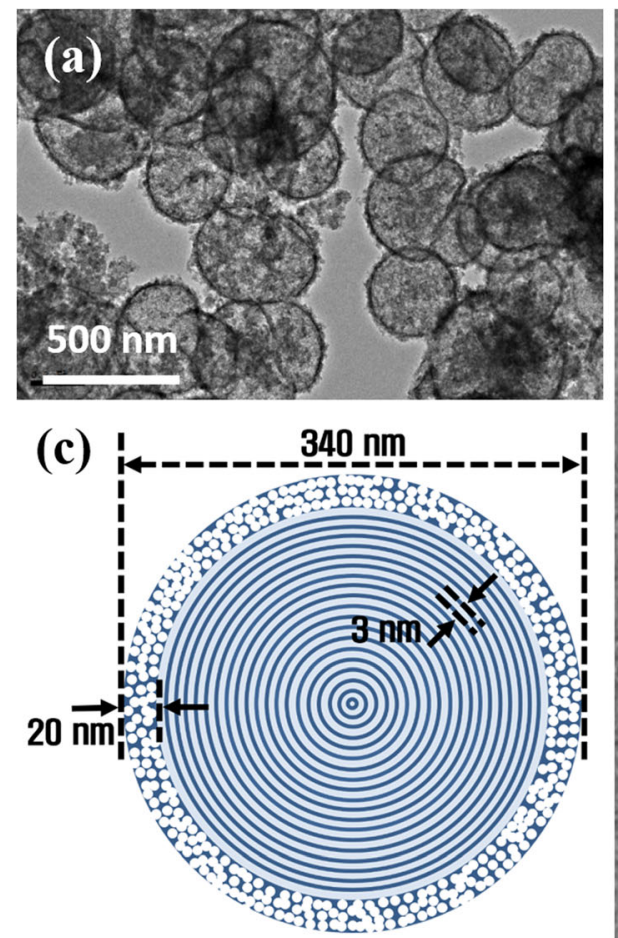

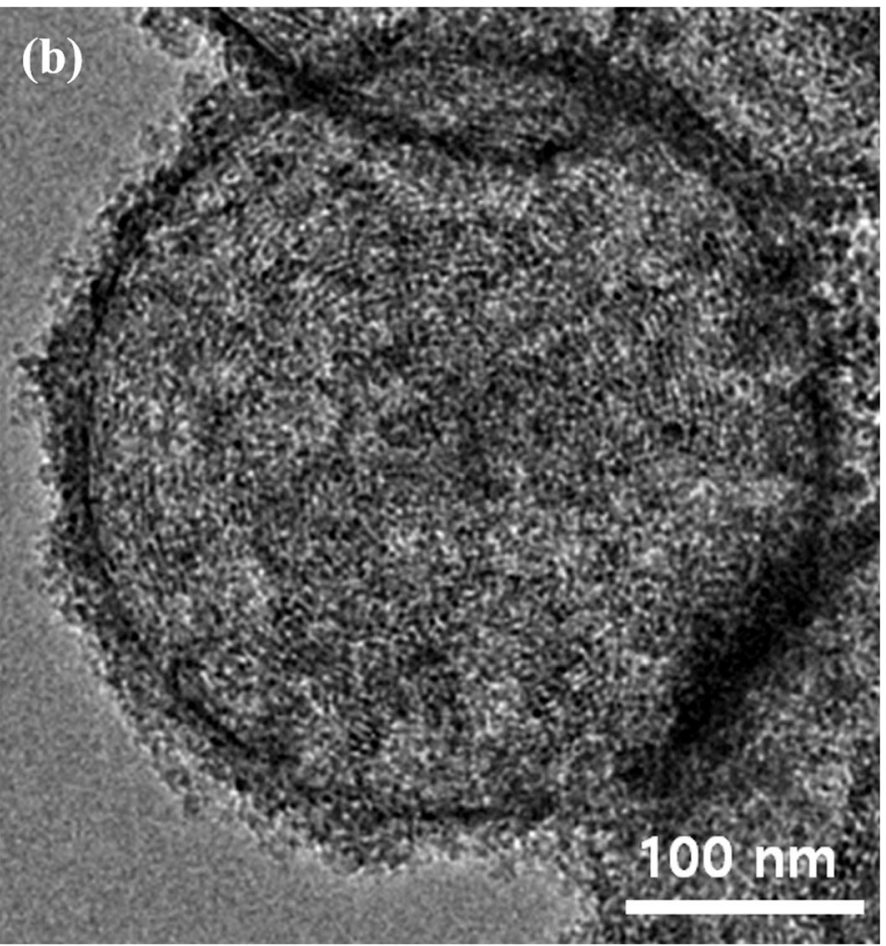

Fig. 6 Low (a) and high (b) magnified TEM images of HMS13-60-48h synthesized at $60{ }^{\circ} \mathrm{C}$ for $48 \mathrm{~h}$. (c) Schematized diagram from nanostructure of multilayered hollow sphere in (b) 
Fig. 7 Low $(a, c)$ and high $(b, d)$ magnified (a,b) SEM and (c,d)

TEM images of HMS10S-60-24h synthesized at $60^{\circ} \mathrm{C}$ for $24 \mathrm{~h}$ with the APFO as single structuredirecting agent without DDAPS HMS10S-60-6h, (b,f) HMS10S60-12h, and (c,g) HMS10S-60$48 \mathrm{~h}$ synthesized at $60{ }^{\circ} \mathrm{C}$ for different reaction time $(6 \mathrm{~h}, 12 \mathrm{~h}$, and $48 \mathrm{~h}$ ), and (d,h) HMS10S-60$6 \mathrm{hF}$ produced with film morphology at the air-water interface after reaction at $60{ }^{\circ} \mathrm{C}$ for $6 \mathrm{~h}$ using APFO as single structure-directing agent without DDAPS
Fig. 8 Low $(a-d)$ and high $(e-h)$ magnified TEM images of $(a, e)$
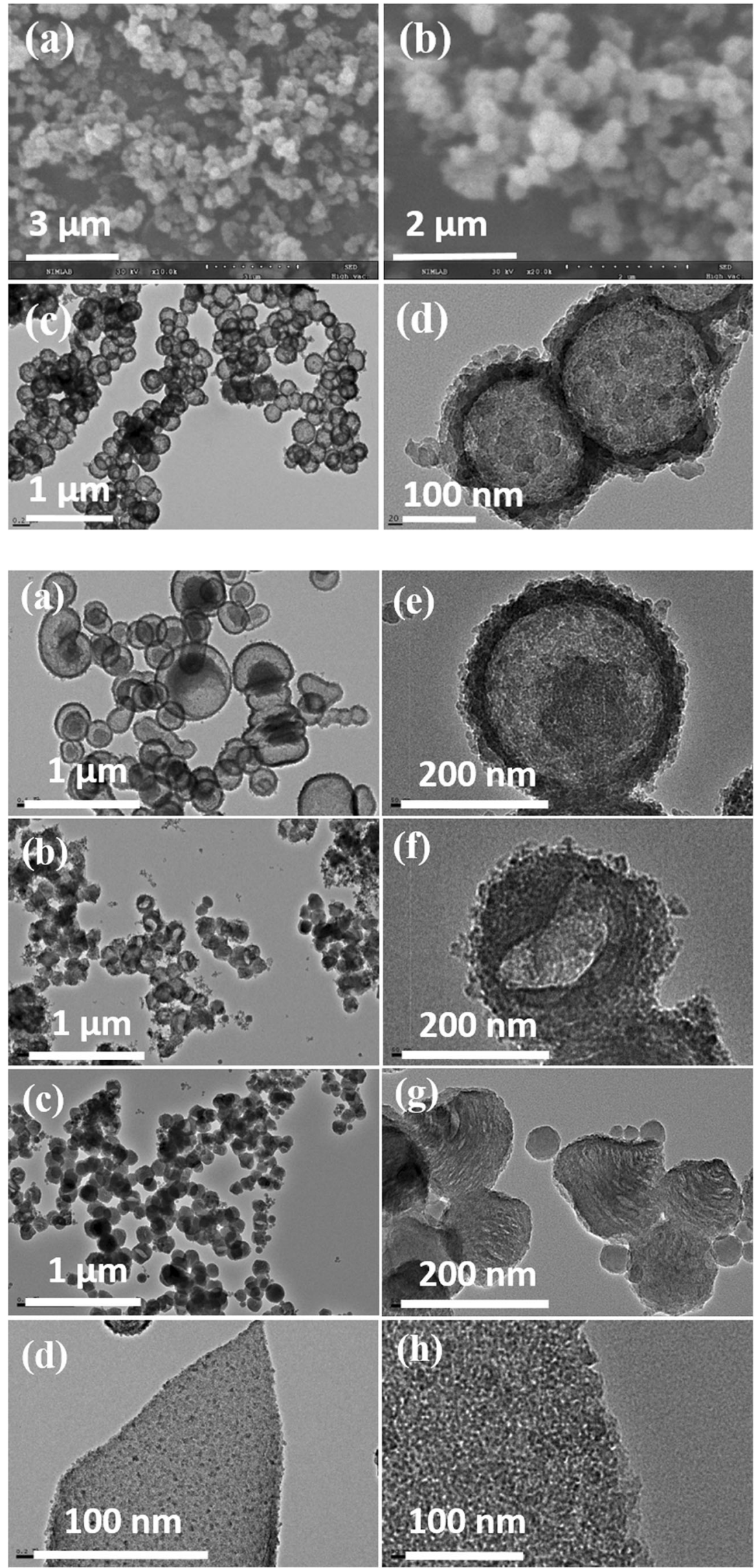

型 Springer 
Fig. 9 Low and high magnified TEM images of $(a, c)$ HMS10S45-24h and (b,d) HMS10S-95$24 \mathrm{~h}$ synthesized at different reaction temperature $\left(45\right.$ and $\left.95^{\circ} \mathrm{C}\right)$ using APFO as single structuredirecting agent without DDAPS
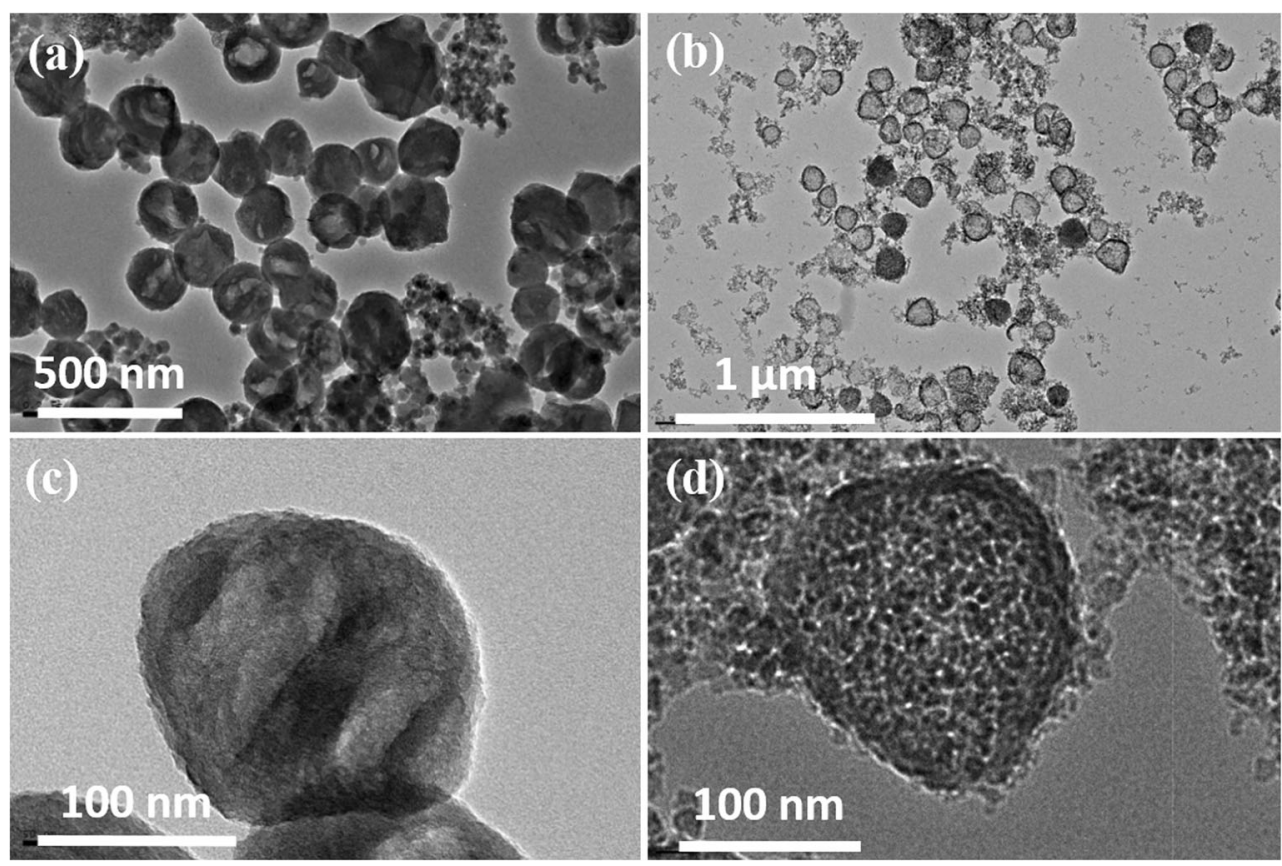

longer reaction times $(>12 \mathrm{~h}$ ), the film did not contain any mesopores, as evidenced in the TEM images (Fig. S18).
Figure 9 exhibits low- and high-magnified TEM images of $(a, c)$ HMS10S-45-24h and (b,d) HMS10S-95-24h synthesized

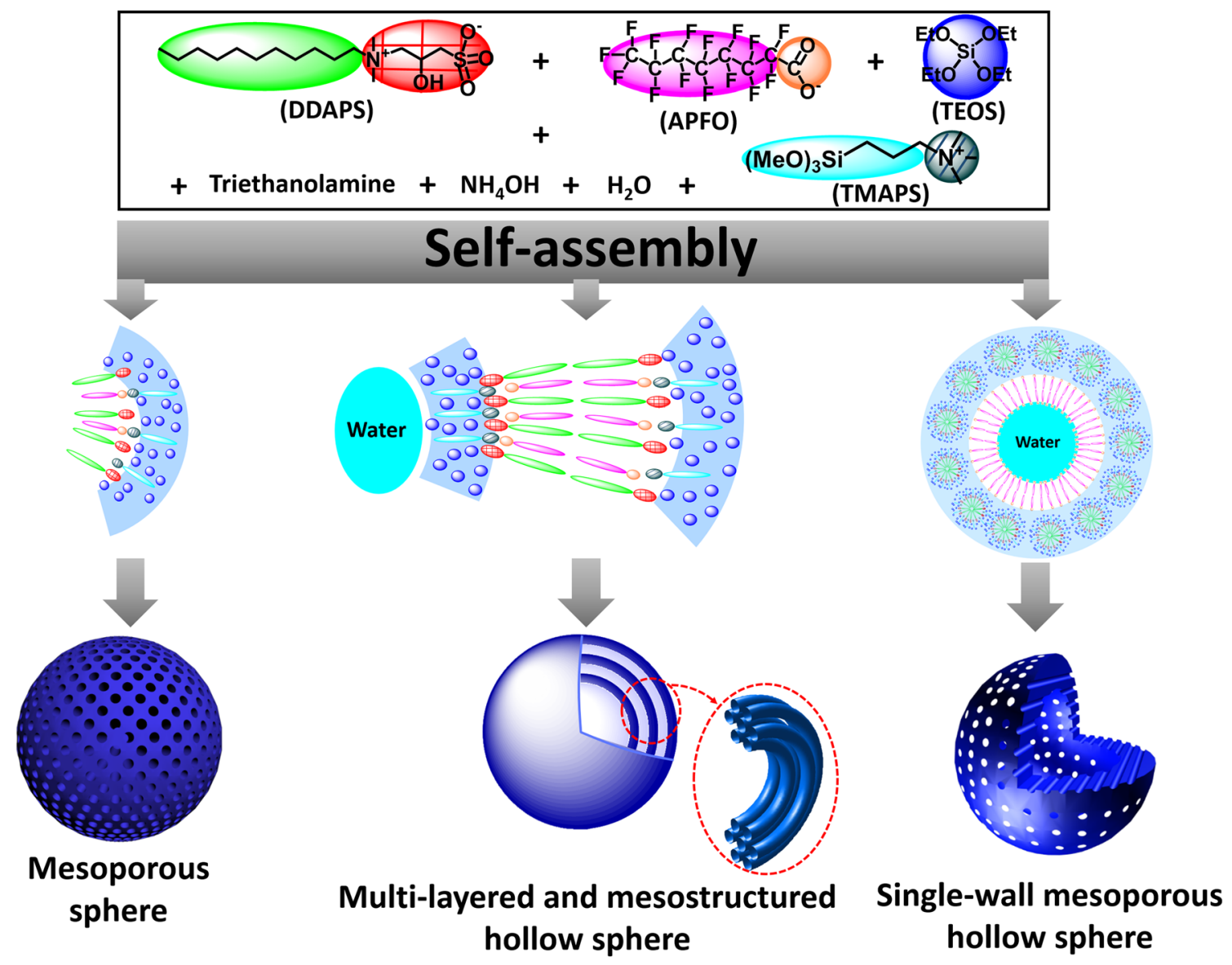

Scheme 2 Schematic illustration of the mechanism of formation of proposed for alkylammonium-functionalized hollow mesoporous silica spheres

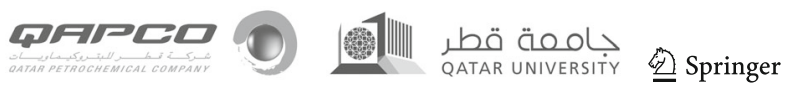


Scheme 3 Schematic illustration of the mechanism of formation of proposed for alkylammoniumfunctionalized mesoporous silica films

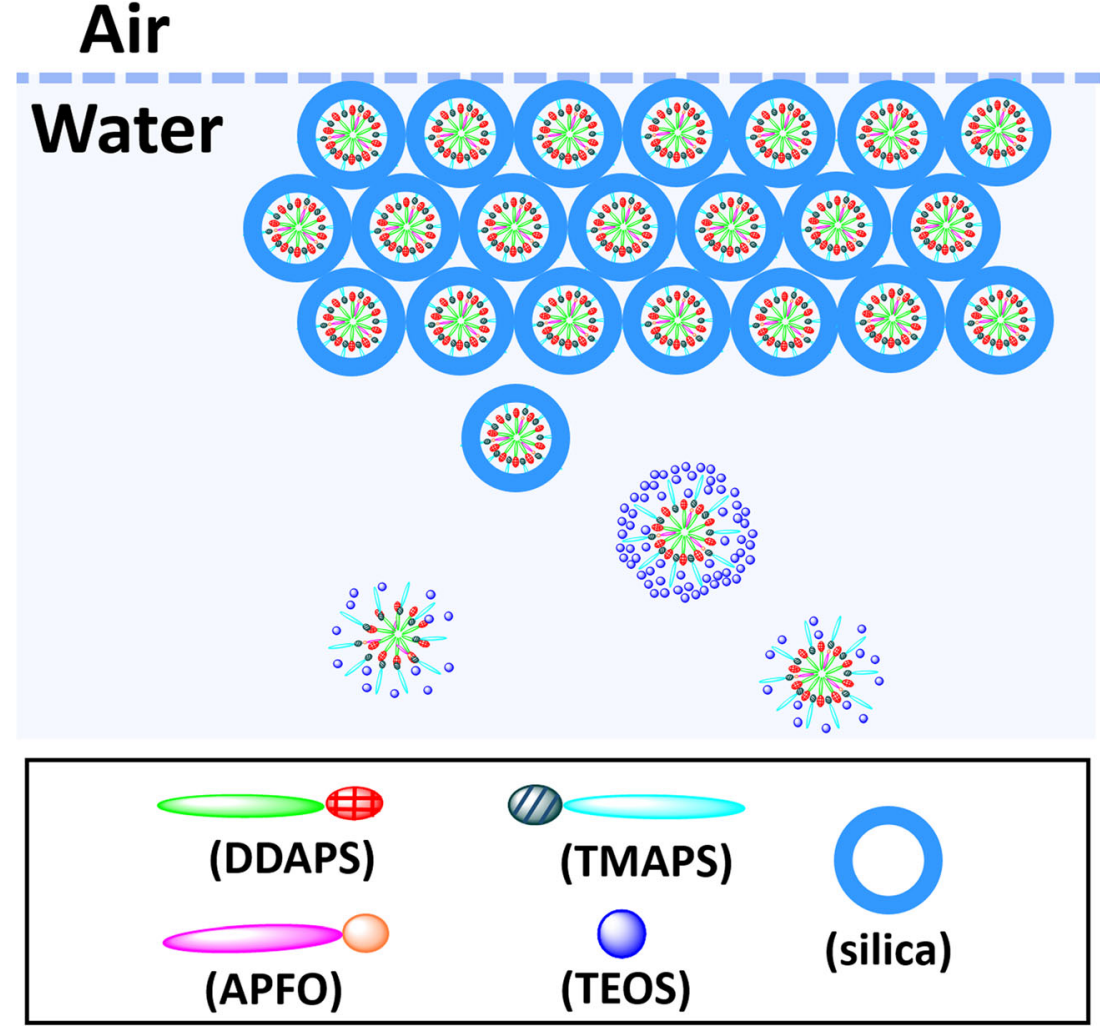

at different reaction temperatures $\left(45\right.$ and $\left.95^{\circ} \mathrm{C}\right)$ using APFO as a single structure-directing agent without DDAPS. At a reaction temperature of $95{ }^{\circ} \mathrm{C}$, alkylammoniumfunctionalized hollow silica particles with a disordered mesostructure in shell were produced with a 96-nm particle size (Fig. 9b,d) These observations were supported by both SEM (Fig. S19(b,d)) and XRD (Fig. S20(b)). In contrast, at a lower reaction temperature $\left(45^{\circ} \mathrm{C}\right)$, hollow particles with a particle size of $155 \mathrm{~nm}$ did not produce any mesopores in the shell, as evidenced by TEM (Fig. 9a,c), SEM (Fig. S19a,c), and XRD (Fig. S20(a)). Under these conditions, a film morphology was not produced at the air-water interface of the reactant solution during the synthesis of the powder samples with spherical morphologies in the bottom of the reaction bottle.

The resulting alkylammonium-functionalized hollow mesoporous silica materials using APFO without DDAPS, TEOS, and alkylammonium alkoxysilane (TMAPS) did not produce a layered mesostructure in the shell. Alkylammonium-functionalized hollow mesoporous silica materials synthesized using DDAPS, APFO, TEOS and TMAPS together, however, produced a layered mesostructure in the shell. Wu et al. [38] reported the synthesis of hollow mesoporous silica particles with rod-like and spherical morphologies using a mixture of zwitterionic (N-dodecyl-N,Ndimethyl-3-ammonio-1-propane sulfonate, DDAPS) and anionic SDS surfactants, TEOS and alkylammonium alkoxysilane (TMAPS). On the other hand, these authors did not report the hollow mesoporous silica with a layered mesostructure in the shell and the mesoporous silica film. Nevertheless, the binary system of organic template using dual surfactants (zwitterionic DDAPS and fluorocarbon anionic APFO) was quite useful for the synthesis of the alkylammonium-functionalized hollow mesoporous silica particles with a layered mesostructure in the shell and the alkylammonium-functionalized mesoporous silica films at the air-water interface.

A mechanism of formation of the mesostructured silica with hollow and film morphologies is proposed. The fluorocarbon anion (ammonium perfluorooctanoate, APFO) plays an important role in the formation of such a hollow morphology and layered shell. The hollow morphologies were produced even using APFO only as a template. The different curvature and interdigitation of the micelles can be observed with increasing amounts of APFO. HMS11-60-24h and HMS31-60-24h synthesized with DDAPS/APFO = 1/1 and $1 / 3$, respectively, exhibited layered hollow structures with circular mesostructures in the shell. With a smaller amount of APFO (DDAPS/APFO =3/1), the mesoporous silica materials were synthesized with cylindrical mesopores via self-assembly, which would be expected for an inorganic precursor as the wall composition and an organic template that is composed of a hydrophilic head and hydrophobic tail in general. With a larger amount of APFO (DDAPS/APFO = 1/9), a circular mesostructure and hollow structure with a layered structure in the shell were destroyed because of the unbalanced 
self-assembly between DDAPS and APFO. The mechanism for the formation of alkylammonium-functionalized hollow mesoporous silica spheres might occur as shown in Scheme 2.

A film is formed due to the difference in the solvent chemical potential between the surrounding atmosphere and the bulk solution [50]. Film-forming solutions also contain a volatile alcohol, such as methanol or ethanol, which arises from the hydrolysis of alkoxysilane (silica precursor). Water evaporation is also sufficient to cause a strong convective flow to the interface. Solvent evaporation at the air-water interface may induce the accumulation of the mesostructured surfactant-silica composites. The accumulation of nonvolatile co-solvents, such as water at the air-water interface, also has an effect, which may either enhance this separation or drive the particles back into the subphase [51]. In the case of the film-forming system, this effect also favors the movement to the surface, and the evaporation of solvents at the air-water interface that leads to a steady decrease in the height of the interface with accumulation at the air-water interface [50]. The hydrophobicity of the material formed in the subphase must also play a role in film growth because silicasurfactant films will form at the air-water interface. The surfactant-templated films grown at the air-water interface for reactant solutions involve either organosilane species or solutions. The silica polymerizes with a more hydrophobic surfactant, which would be expected to be considerably more hydrophobic than the silica-surfactant composites [43-46]. In summary, Scheme 3 shows the proposed mechanism of the formation of films synthesized in this work. It should be noted, however, that further experimental studies are needed to explain more exactly on the mesoporous silica films generated at the air/water surface. We will carry out more detailed studies on the subject to explain the formation mechanism of the films with more experimental results in our future work.

\section{Conclusions}

Alkylammonium-functionalized hollow mesoporous silica particles and mesoporous silica films were synthesized by a onepot sol-gel approach via a self-assembly and hydrothermal reaction of N-trimethoxysilylpropyl-N,N,N-trimethylammonium chloride (TMAPS) and tetraethoxysilane (TEOS) as the silica precursors, and dodecyldimethyl(3-sulfopropyl)ammonium hydroxide (DDAPS) and fluorocarbon anion (ammonium perfluorooctanoate (APFO)) as the structure-directing agents. The alkylammonium-functionalized hollow mesoporous silica particles displayed different morphologies, mesoporosities, and hollow structures with layered shells under a range of reaction conditions (e.g., different surfactant DDAPS/APFO molar ratios, different reaction times, and temperatures). Interestingly, the alkylammonium-functionalized mesoporous silica films were obtained at the air-water interface, whereas the hollow mesoporous silica particles were produced with precipitation in the bottom of the reaction bottle. This was not reported for the hollow mesoporous silica particles with a layered mesostructure in the shell in the bottom of the reaction bottle and the mesoporous silica film grown at the air-water interface via self-assembly and hydrothermal reaction process in the same reaction bottle. The alkylammonium-functionalized mesoporous silica materials with a hollow sphere and film morphologies that simultaneously possess large pores inside the shells and mesopores at the shells can be quite attractive for a range of application fields, such as confined catalysis, biomedicine (including drug delivery), bioimaging, cancer cell detection, biosensing, adsorption of protein and virus, and low- $k$ application, because of their large void space fraction, high surface area, and functionality of shells.

Funding information The work was supported by the National Research Foundation of Korea (NRF) Grant funded by the Ministry of Science and ICT, Korea Mid-Career Researchers Program (NRF2017R1A2B3012961); Individual Basic Research Program (NRF2017R1D1AB03034414); Brain Korea 21 Plus Program (21A2013800002)\}.

\section{Compliance with ethical standards}

Conflict of interests The authors declare that they have no conflict of interest.

Open Access This article is distributed under the terms of the Creative Commons Attribution 4.0 International License (http:// creativecommons.org/licenses/by/4.0/), which permits unrestricted use, distribution, and reproduction in any medium, provided you give appropriate credit to the original author(s) and the source, provide a link to the Creative Commons license, and indicate if changes were made.

\section{References}

1. S.S. Park, M.S. Moorthy, C.-S. Ha, NPG Asia Mater. 6(e96), 1-21 (2014)

2. S.S. Park, C.-S. Ha, Chem. Rec. 6, 32-42 (2006)

3. S.S. Park, M.S. Moorthy, S.-W. Chu, F. Dong, W. Guo, C.-S. Ha, Adv. Porous Mater. 1, 4-33 (2013)

4. Y. Li, J. Shi, Adv. Mater. 26, 3176-3205 (2014)

5. Z. Chen, Z.-M. Cui, F. Niu, L. Jiang, W.-G. Song, Chem. Commun. 46, 6524-6526 (2010)

6. J. Dou, H.C. Zeng, J. Am. Chem. Soc. 134, 16235-16246 (2012)

7. X. Fang, Z. Liu, M.-F. Hsieh, M. Chen, P. Liu, C. Chen, N. Zheng, ACS Nano 6, 4434-4444 (2012)

8. J. Liu, H.Q. Yang, F. Kleitz, Z.G. Chen, T.Y. Yang, E. Strounina, G.Q. Lu, S.Z. Qiao, Adv. Funct. Mater. 22, 591-599 (2012)

9. X. Fang, X. Zhao, W. Fang, C. Chen, N. Zheng, Nanoscale 5, 2205-2218 (2013)

10. Y. Chen, H. Chen, J. Shi, Adv. Porous Mater. 1, 34-62 (2013)

11. T. Wen, B. Yang, Y. Guo, J. Sun, C. Zhao, S. Zhang, M. Zhang, Y. Wang, Phys. Chem. Chem. Phys. 16, 23188-23195 (2014)

12. C.-J. Tsou, C.-Y. Chu, Y. Hung, C.-Y. Mou, J. Mater. Chem. B 1, 5557-5563 (2013)

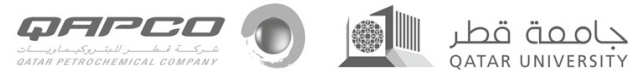


13. T. Wang, L. Zhang, Z. Su, C. Wang, Y. Liao, Q. Fu, ACS Appl. Mater. Interfaces 3, 2479-2486 (2011)

14. D. Mahony, A.S. Cavallaro, K.T. Mody, L. Xiong, T.J. Mahony, S.Z. Qiao, N. Mitter, Nanoscale 6, 6617-6626 (2014)

15. S.J. Lee, M.-C. Choi, S.S. Park, C.-S. Ha, Macromol. Res. 19(6), 599-607 (2011)

16. R.K. Rana, Y. Mastai, A. Gedanken, Adv. Mater. 14, 1414-1418 (2002)

17. C.E. Fowler, D. Khushalani, S. Mann, Chem. Commun., 20282029 (2001)

18. Y. Li, J. Shi, Z. Hua, H. Chen, M. Ruan, D. Yan, Nano Lett. 3, 609$612(2003)$

19. J. Wang, Q. Xiao, H. Zhou, P. Sun, Z. Yuan, B. Li, D. Ding, A.C. Shi, T. Chen, Adv. Mater. 18, 3284-3288 (2006)

20. Z. Feng, Y. Li, D. Niu, L. Li, W. Zhao, H. Chen, L. Li, J. Gao, M. Ruan, J. Shi, Chem. Commun., 2629-2631 (2008)

21. J.G. Wang, F. Li, H.J. Zhou, P.C. Sun, D.T. Ding, T.H. Chen, Chem. Mater. 21, 612-620 (2009)

22. B. Tan, H.J. Lehmler, S.M. Vyas, B.L. Knutson, S.E. Rankin, Adv. Mater. 17, 2368-2371 (2005)

23. B. Tan, S.M. Vyas, H.-J. Lehmler, B.L. Knutson, S.E. Rankin, Adv. Funct. Mater. 17, 2500-2508 (2007)

24. H. Djojoputro, X.F. Zhou, S.Z. Qiao, L.Z. Wang, C.Z. Yu, G.Q. Lu, J. Am. Chem. Soc. 128, 6320-6321 (2006)

25. C.X. Lin, Y. Jin, Z. Li, Z. Yan, Z. Hao, Y. Huang, G.Q. Lu, J. Phys. Chem. C 113, 8673-8682 (2009)

26. J.S. Liu, B. Hartono, Y.G. Jin, Z. Li, G.Q. Lu, S.Z. Qiao, J. Mater. Chem. 20, 4595-4601 (2010)

27. Z. Chen, D. Niu, Y. Li, J. Shi, RSC Adv. 3, 6767-6770 (2013)

28. G. Zhu, S. Qiu, O. Terasaki, Y. Wei, J. Am. Chem. Soc. 123, 77237724 (2001)

29. G. Qi, Y. Wang, L. Estevez, A.K. Switzer, X. Duan, X. Yang, E.P. Giannelis, Chem. Mater. 22, 2693-2695 (2010)

30. Y. Chen, H. Chen, L. Guo, Q. He, F. Chen, J. Zhou, J. Feng, J. Shi, ACS Nano 4(1), 529-539 (2010)

31. Y. Zhu, E. Kockrick, T. Ikoma, N. Hanagata, S. Kaskel, Chem. Mater. 21, 2547-2553 (2009)
32. W. Zhao, M. Lang, Y. Li, L. Li, J. Shi, J. Mater. Chem. 19, 2778 $2783(2009)$

33. Z. Teng, Y. Han, J. Li, F. Yan, W. Yang, Micropor. Mesopor. Mater. 127, 67-72 (2010)

34. M. Mandal, M. Kruk, Chem. Mater. 24, 123-132 (2012)

35. L. Zhang, S. Qiao, Y. Jin, Z. Chen, H. Gu, G.Q. Lu, Adv. Mater. 20, 805-809 (2008)

36. M. Li, C. Zhang, X.-L. Yang, H.-B. Xu, RSC Adv. 3, 16304-16307 (2013)

37. A. Zhang, Y. Zhang, N. Xing, K. Hou, X. Guo, Chem. Mater. 21, 4122-4126 (2009)

38. X.-J. Wu, Y. Jiang, D. Xu, J. Phys, Chem. C 115, 11342-11347 (2011)

39. X. Wu, C.M. Crudden, Chem. Mater. 24, 3839-3846 (2012)

40. Y.-Q. Yeh, B.-C. Chen, H.-P. Lin, C.-Y. Tang, Langmuir 22, 6-9 (2006)

41. G. Kostov, F. Boschet, B. Ameduri, J. Fluor. Chem. 130, 1192 1199 (2009)

42. H. Yang, N. Coombs, I. Sokolov, G.A. Ozin, Nature 381, 589-592 (1996)

43. S.S. Park, C.-S. Ha, Chem. Commun., 1986-1987 (2004)

44. S.S. Park, C.-S. Ha, Chem. Mater. 17, 3519-3523 (2005)

45. S.S. Park, D.H. Park, C.-S. Ha, Chem. Mater. 19, 2709-2711 (2007)

46. S.S. Park, J.H. Shin, D. Zhao, C.-S. Ha, J. Mater. Chem. 20, 7854 $7858(2010)$

47. S. Brunauer, P.H. Emmet, E. Teller, J. Am. Chem. Soc. 60, 309 319 (1938)

48. K.S. Sing, D.H. Everett, R.A.W. Haul, L. Moscou, R.A. Pierotti, J. Rouquerol, T. Siemieniewska, Pure Appl. Chem. 57, 603-619 (1985)

49. P.T. Tanev, T.J. Pinnavaia, Science 271, 1267-1269 (1996)

50. K.J. Edler, B. Yang, Chem. Soc. Rev. 42, 3765-3776 (2013)

51. A. Kabalnov, H. Wennerstrom, Soft Matter 5, 4712-4718 (2009) 